\title{
Longitudinal pericardial adipose tissue changes in patients with breast cancer receiving anthracycline-based chemotherapy: a retrospective cohort study
}

\author{
Qiuzhi Chen ${ }^{1 \#}$, Chunrong Tu ${ }^{1 \#}$, Xiaoqin Li $^{1}$, Hesong Shen ${ }^{1}$, Xing Wang ${ }^{1}$, Daihong Liu ${ }^{1}$, Yu Wang ${ }^{1}$, \\ Renwei Liu ${ }^{1}$, Wei Den ${ }^{1}$, Xiaoyue Zhang ${ }^{2}$, Jiuquan Zhang ${ }^{1}$ \\ ${ }^{1}$ Department of Radiology, Chongqing University Cancer Hospital and Chongqing Cancer Institute and Chongqing Cancer Hospital, Chongqing, China; \\ ${ }^{2}$ Siemens Healthineers, Xi'an, China
}

Contributions: (I) Conception and design: Q Chen, C Tu; (II) Administrative support: J Zhang; (III) Provision of study materials or patients: W Den, X Li, X Wang, R Liu; (IV) Collection and assembly of data: Y Wang, X Li; (V) Data analysis and interpretation: X Yuan, Y Wang; (VI) Manuscript writing: All authors; (VII) Final approval of manuscript: All authors.

${ }^{\#}$ These authors contributed equally to this work.

Correspondence to: Jiuquan Zhang. Department of Radiology, Chongqing University Cancer Hospital and Chongqing Cancer Institute and Chongqing Cancer Hospital, Chongqing 400030, China. Email: zhangjq_radiol@foxmail.com.

Background: Pericardial adipose tissue (PAT) has been associated with adverse cardiac events. In this study, we evaluated changes of PAT in patients with breast cancer during and after anthracycline-based chemotherapy and explored the clinical variables associated with increases in PAT volume at the completion of chemotherapy.

Methods: A total of 278 breast cancer patients who were receiving anthracycline-based chemotherapy were retrospectively enrolled. Their PAT volumes were measured using non-contrast chest computed tomography (CT) images from a dedicated workstation. We compared these volumes to their measurements at baseline, during different chemotherapy cycles, at and after chemotherapy completion. We identified the clinical variables associated with increases in PAT volume at chemotherapy completion using logistic regression analyses.

Results: At the completion of chemotherapy, PAT volumes were shown to have increased compared to baseline measurements $\left(87.67 \pm 45.09\right.$ vs. $\left.104.25 \pm 47.74 \mathrm{~cm}^{3} ; \mathrm{P}=0.00\right)$. After 4,6 , and 8 chemotherapy cycles, PAT volumes increased from the baseline measurement by $9.48 \%$ [95\% confidence interval (CI): $-2.30 \%$ to $21.27 \%$ ], $14.75 \%$ (95\% CI: $4.68 \%$ to $24.82 \%$ ), and $20.02 \%$ (95\% CI: $11.38 \%$ to $28.66 \%$ ), respectively. Compared to volumes measured at chemotherapy completion $\left(104.25 \pm 47.74 \mathrm{~cm}^{3}\right)$, PAT volumes at 6 and 12 months after chemotherapy completion were $105.23 \pm 49.27$ and $107.56 \pm 46.34 \mathrm{~cm}^{3}$, respectively. The differences between chemotherapy completion and follow-up PAT volumes were not statistically significant. A variable associated with an increase in PAT from baseline to chemotherapy completion was the number of chemotherapy cycles (8 vs. 4) [odds ratio (OR) $=3.850$; 95\% CI: 1.751 to 8.488].

Conclusions: Patients with breast cancer who undergo anthracycline-based chemotherapy can experience unfavorable PAT volume increases, which are maintained after the completion of treatment. Patients at risk of increases in PAT volume at chemotherapy completion can be identified based on clinical risk factors and targeted for interventions.

Keywords: Pericardial adipose tissue (PAT); anthracyclines; breast cancer 
Submitted Aug 02, 2021. Accepted for publication Dec 10, 2021; Published online: 11 Jan 2022.

doi: 10.21037 /qims-21-787

View this article at: https://dx.doi.org/10.21037/qims-21-787

\section{Introduction}

Pericardial adipose tissue (PAT), a visceral fat deposit surrounding the heart, includes paracardial and epicardial adipose tissue (EAT). The EAT is located between the visceral layer of the myocardium and the pericardium, primarily in the atrioventricular and ventricular grooves of the heart and around the coronary artery, and is characteristically brown or beige (1). As it has a higher capacity for fatty acid uptake and release, EAT is important for maintaining myocardial metabolism (2). In addition, the mechanical and thermal properties of EAT also protect the myocardium, preventing changes in the myocardial structure and temperature during the contraction phase of the cardiac cycle (3).

However, increased EAT can lead to harmful lipotoxic and inflammatory factors that cause functional and organic damage to the cardiovascular system under pathological conditions. Many studies have shown that EAT volume correlates positively with the occurrence of coronary heart disease (4) and ventricular arrhythmia (5). It can also directly affect the diastolic function of the left ventricle $(6,7)$. Increased cardiac visceral fat, particularly EAT, has been proposed as a new cardio-metabolic risk factor (8). According to a systematic review, EAT thickness $>5 \mathrm{~mm}$, or volume $>125 \mathrm{~mL}$ or $68 \mathrm{~mL} / \mathrm{m}^{2}$ might be considered a risk factor for metabolic syndrome and coronary artery disease (9).

Anthracyclines are a frontline breast cancer treatment. In the process of killing tumor cells, anthracyclines also affect the synthesis of glutathione and weaken antioxidant capacity, resulting in the generation of excessive free radicals and interference with fatty acid metabolism. In the liver, anthracyclines can cause enzyme abnormalities, which will affect the transport of lipids by very-low-density lipoprotein (VLDL) from the liver to the plasma. This may result in a decrease in palmitic and oleic acids and lead to drug-induced steatohepatitis. Studies have shown that EAT is associated with the presence and progression of non-alcoholic fatty liver disease. The EAT acts as an endocrine or paracrine organ and produces proinflammatory adipokines and interleukins such as vaspin, tumor necrosis factor- $\alpha(\mathrm{TNF}-\alpha)$, interleukin-6 (IL-6), interleukin-17 (IL-17), and angiotensin, all of which are involved in the development and progression of both cardiovascular and fatty liver diseases (10).

Previous studies have shown that intermuscular, visceral, and subcutaneous fats are significantly higher at chemotherapy completion than at baseline in patients receiving anthracyclines $(11,12)$. However, the reasons for the changes to PAT in these patients remain unclear. In this study, we described the longitudinal changes in PAT in breast cancer patients undergoing anthracycline-based therapy and explored the potential risk factors associated with long-term increases in PAT volume.

We present the following article in accordance with the Strengthening the Reporting of Observational Studies in Epidemiology (STROBE) checklist (available at https://qims. amegroups.com/article/view/10.21037/qims-21-787/rc).

\section{Methods}

\section{Study population}

The study was conducted in accordance with the Declaration of Helsinki (as revised in 2013). This retrospective study was approved by the ethics committee at Chongqing University Cancer Hospital, and individual consent for this retrospective analysis was waived.

The study cohort included female patients with breast cancer who had received anthracycline-based chemotherapy (doxorubicin, epirubicin, or pirarubicin) in 3-4-week cycles for more than 4 cycles from January 2018 to December 2019. Patients had undergone chest computed tomography (CT) scans within 2 weeks before and after completing chemotherapy. The exclusion criteria for the study were as follows: previous chemotherapy, heavy motion artifacts, coronary artery stent or bypass, or pericardial effusion. Cases were deemed eligible by 2 doctors with at least 3 years of experience in cardiac imaging. Overall, 278 female patients with breast cancer were included in the study.

Patients who had had chest CT scans at 6 and 12 months after chemotherapy were included in the follow-up. The following data recorded before chemotherapy and at chemotherapy completion were collected the from the patients' medical records: age, height and weight, gender, blood glucose, blood pressure, disease stage, pathological type, chemotherapy drugs and cycles, blood lipids, and liver function.

According to predefined criteria, diabetes (13) was diagnosed if oral glucose tolerance test (OGTT) fasting 

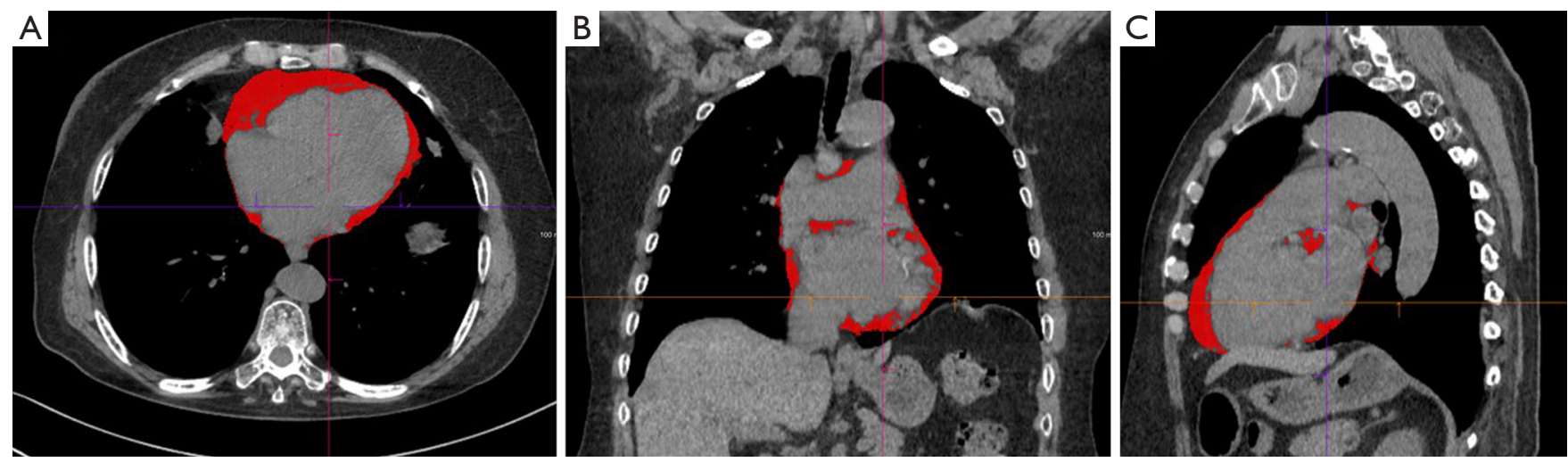

Figure 1 Sample of PAT measurements. A non-contrast CT chest image was used. (A) Axial plane. (B) Coronal plane. (C) Sagittal plane. PAT volume was measured at the red area. CT values for the red area were from -150 to $-50 \mathrm{HU}$. PAT, pericardial adipose tissue; CT, computed tomography.

blood glucose levels were $>7.0 \mathrm{mmol} / \mathrm{L}$, if blood glucose levels were $>11.1 \mathrm{mmol} / \mathrm{L} 2$ hours after a meal, or if the typical symptoms of diabetes were detected and random blood glucose levels were $>11.1 \mathrm{mmol} / \mathrm{L}$. Similarly, hypertension (14) was diagnosed if systolic blood pressure was $>130 \mathrm{mmHg}$ and/or diastolic blood pressure was $>80 \mathrm{mmHg}$. Body mass index (BMI) was calculated as weight $(\mathrm{kg}) /$ square of height $\left(\mathrm{m}^{2}\right)$ using patient weight and height on the first day of hospitalization. Participants were classified into 3 BMI-based categories according to the modified World Health Organization (WHO) criteria: underweight $\left(<18.5 \mathrm{~kg} / \mathrm{m}^{2}\right)$, normal range (18.5 to $\left.<25 \mathrm{~kg} / \mathrm{m}^{2}\right)$, and obese $\left(\geq 25 \mathrm{~kg} / \mathrm{m}^{2}\right)(15)$.

\section{CT protocols}

Case examinations were performed using 1 of 2 64-multidetector CT scanners (SOMATOM Definition AS+, Siemens Healthineers, Erlangen, Germany; Brilliance 40, Philips Healthcare, Amsterdam, The Netherlands). The SOMATOM Definition AS+ parameters were as follows: tube voltage, $120 \mathrm{kVp}$; reference tube current, $110 \mathrm{mAs}$; detector collimation, $128 \times 0.6 \mathrm{~mm}$; pitch, 1.2 ; matrix, $512 \times 512$; thickness, $1 \mathrm{~mm}$; and increment, $0.7 \mathrm{~mm}$. The sinogram affirmed iterative reconstruction (SAFIRE) image data reconstruction method was used, and imaging data were reconstructed using a mediastinum algorithm. The Brilliance 40 parameters were as follows: tube voltage, $120 \mathrm{kVp}$; reference tube current, $110 \mathrm{mAs}$; detector collimation, $64 \times 0.625 \mathrm{~mm}$; pitch, 1.2 ; matrix, $512 \times 512$; thickness, $1 \mathrm{~mm}$; and increment, $0.7 \mathrm{~mm}$. The iDOSE level 3 image data reconstruction method was used, and imaging data were reconstructed using a mediastinum algorithm.

\section{Measurements of PAT}

We used non-contrast CT chest images to quantify PAT volumes. Images were reconstructed with $1-\mathrm{mm}$ slice thicknesses and copied to a semiautomated software program (syngo.via Frontier cardiac risk assessment, Siemens Healthineers). PAT was defined as epicardial fat (adipose tissue within the pericardium) plus paracardial fat (adipose tissue on the external surface of the parietal pericardium voxels with CT values between -150 and -50 Hounsfield units (HU) was taken to indicate adipose tissue. We defined the upper limit of the image as the lower edge of the pulmonary bifurcation and the last image in which the heart appeared as the lower limit of PAT. Once PAT was identified, its volume $\left(\mathrm{cm}^{3}\right)$ was calculated automatically (Figure 1). These measurements were taken by 2 radiologists with at least 3 years of experience in chestimaging diagnosis.

We calculated the increase in PAT volume using the following formula: PAT volume at chemotherapy completion-PAT volume at baseline. We classified the increase in PAT volume into 4 levels, according to the interquartile range (IQR) and taking the increases in PAT volume as ordered categorical variables.

\section{Measurements of hepatic/splenic density ratios}

We selected the images at the hilar level to measure the 


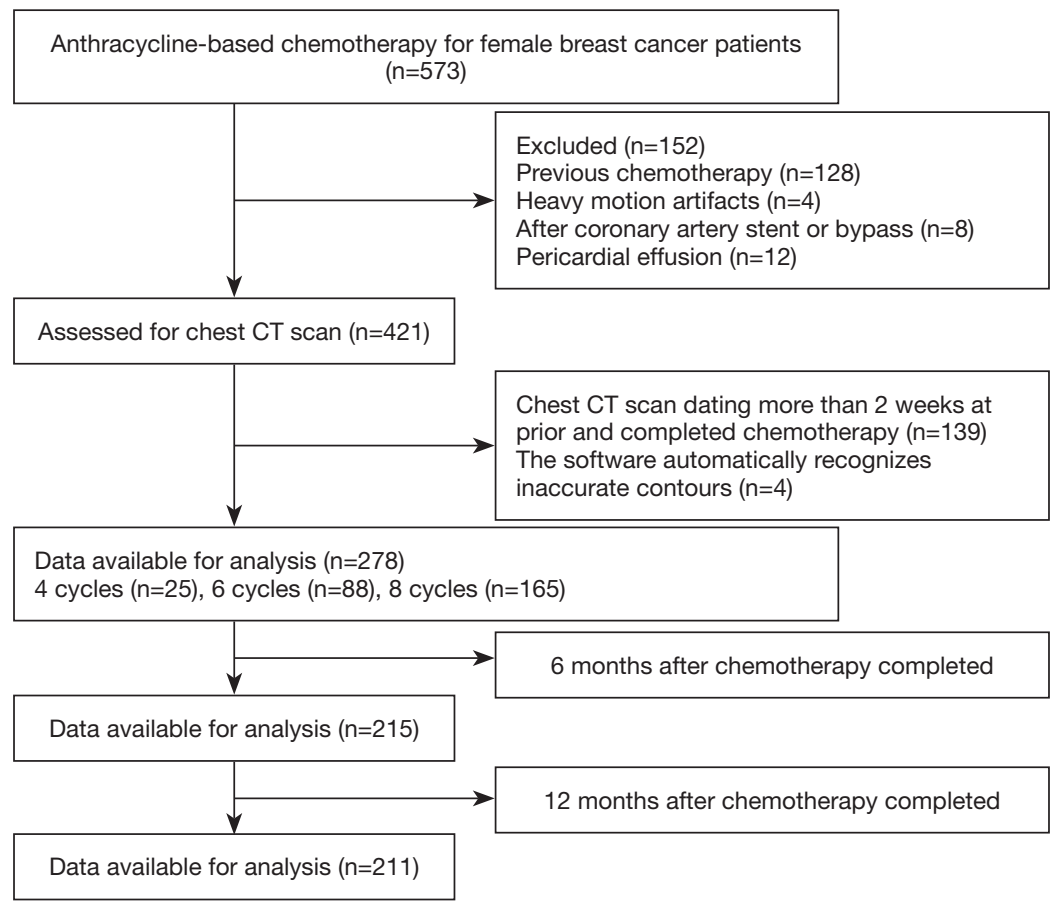

Figure 2 STROBE diagram. CT, computed tomography; STROBE, Strengthening the Reporting of Observational Studies in Epidemiology.

CT values of the liver and spleen. If the hilar level was not covered in the scan, we selected the maximum level of the spleen. Our measurements avoided the blood vessels as much as possible (16). For each patient, we set a region of interest (ROI) of $1 \mathrm{~cm}^{2}$ and manually drew 3 ROIs within the middle of the spleen and liver. We used the mean of the 3 ROIs to calculate the hepatic/splenic density ratios.

\section{Statistical analyses}

We performed statistical analyses using SPSS software version 25.0 (IBM Corp., Armonk, NY, USA). Continuous variables were described as means \pm standard deviations or medians (IQRs), and categorical variables were described as numbers and percentages. We used paired $t$-tests and Wilcoxon tests to compare blood lipids, liver function, blood glucose, and PAT volumes at baseline and chemotherapy completion. We used the repeated analysis of variance (ANOVA) to evaluate changes in PAT volumes of the 4 cycles and at different points in the chemotherapy cycles. Univariate logistic regression analysis evaluated the variables associated with increased PAT volume at chemotherapy completion. We entered variables with a $\mathrm{P}$ value of $<0.20$ into a multivariable logistic regression model. A P value of $<0.05$ was considered statistically significant.

\section{Results}

\section{Patient demographics}

We initially identified 573 patients who had been treated with anthracycline for breast cancer. When the exclusion criteria were applied (Figure 2), 295 patients were excluded, leaving a total of 278 patients for inclusion in this study. Among those 278 patients, doxorubicin was administered to 65 , epirubicin to 158 , and pirarubicin to 55 . There were no statistical differences in the baseline characteristics of these 3 groups (Table S1). Among the cohort, 25 cases completed 4 cycles of chemotherapy, 88 completed 6 cycles, and 165 completed 8 cycles (Figure 2). Some cases underwent multiple chest CT scans during chemotherapy. A total of 90 cases had a chest CT scan at the 4th cycle, 91 at the 6th cycle, and 165 at the 8 th cycle. Of the participants who had completed all chemotherapy cycles, 215 had chest CT scans available for analysis at 6 months after completion of treatment, and 211 had chest CT scans available for analysis at 12 months after completion of treatment (Figure 2). 
Table 1 Patient clinical and demographic characteristics

\begin{tabular}{|c|c|c|}
\hline Demographic characteristics of patients $(n=278)$ & Clinical characteristics at baseline & Clinical characteristics at chemotherapy completion \\
\hline Female, n (\%) & $278(100.0)$ & $278(100.0)$ \\
\hline Height, mean $\pm \mathrm{SD}, \mathrm{cm}$ & $155.58 \pm 5.87$ & $155.58 \pm 5.87$ \\
\hline Weight, mean $\pm \mathrm{SD}$, kg & $60.12 \pm 8.77$ & $62.89 \pm 9.03$ \\
\hline$<18.5 \mathrm{~kg} / \mathrm{m}^{2}$ & $1(0.4)$ & $1(0.4)$ \\
\hline 18.5 to $<25 \mathrm{~kg} / \mathrm{m}^{2}$ & $153(55.0)$ & $148(53.2)$ \\
\hline$\geq 25 \mathrm{~kg} / \mathrm{m}^{2}$ & $124(44.6)$ & $129(46.4)$ \\
\hline Hypertension, n (\%) & $141(50.7)$ & $141(50.7)$ \\
\hline Invasive carcinoma, n (\%) & $278(100.0)$ & \\
\hline \multicolumn{3}{|l|}{ Stage, n (\%) } \\
\hline $\mathrm{T} 1$ & $69(24.8)$ & \\
\hline T2 & $138(49.6)$ & \\
\hline T3 & $20(7.2)$ & \\
\hline $\mathrm{T} 4$ & $35(12.6)$ & \\
\hline Unknown & $16(5.8)$ & \\
\hline
\end{tabular}

SD, standard deviations; BMI, body mass index; CT, computed tomography.

Table 1 presents the baseline characteristics of the study cohort. All patients were female $(47.88 \pm 7.14$ years) and had invasive carcinoma. A total of 124 patients had a BMI of $\geq 25 \mathrm{~kg} / \mathrm{m}^{2}$. Only 30 patients had a hepatic/splenic ratio of >1.0. Overall, 69 patients had clinical stage T1 cancer, 138 had stage T2, 20 had stage T3, and 35 had stage T4. The clinical stage was unknown for 16 patients.

\section{PAT volume and trends in clinical characteristics}

Differences in PAT volumes measured at baseline and at chemotherapy completion were $87.67 \pm 45.09$ vs. $104.25 \pm 47.74 \mathrm{~cm}^{3}(\mathrm{P}=0.00)$ (Table 2). The PAT volumes at 6 months after chemotherapy completion were $105.23 \pm 49.27 \mathrm{~cm}^{3}$, and at 12 months after chemotherapy completion were $107.56 \pm 46.34 \mathrm{~cm}^{3}$. The differences between these values were not statistically significant (Figure 3). The PAT volumes in all the chemotherapy cycles were higher than at the baseline, especially in the 6th and 8th cycles $(\mathrm{P}<0.05)$ (Figure 4).

Cholesterol (Chol), triglycerides (TG), low-density lipoprotein (LDL), alanine aminotransferase (ALT), and aspartate aminotransferase (AST) at chemotherapy completion were all higher than at baseline (all $\mathrm{P}<0.05$ ). High-density lipoprotein (HDL) had a decreasing trend, but it was not statistically significant $(\mathrm{P}=0.058)$. Total protein significantly decreased $(\mathrm{P}=0.013)$, and the hepatic/ splenic density ratio was significantly lower at baseline than at chemotherapy completion (Table 2).

\section{Variables associated with increased PAT volumes}

Increases in PAT volume from baseline to chemotherapy completion were divided into 4 levels according to IQRs $\left(5.83,15.71\right.$, and $\left.28.64 \mathrm{~cm}^{3}\right)$. To identify the risk factors for increased PAT volumes at chemotherapy completion, we analyzed the patients' baseline and chemotherapy completion scans $(n=278)$. In the univariate logistic 
Table 2 Patient clinical characteristics and PAT comparisons before chemotherapy and at chemotherapy completion

\begin{tabular}{lccc}
\hline Clinical characteristics and PAT volume & Before chemotherapy & At completion & P value \\
\hline TG $(n=78)$ & $1.05(0.82,1.72)$ & $1.59(1.11,2.01)$ & 0.000 \\
Chol $(n=78)$ & $4.73(4.17,5.42)$ & $4.96(4.35,5.36)$ & 0.041 \\
HDL $(n=78)$ & $1.57(1.38,1.76)$ & $1.43(1.31,1.68)$ & 0.058 \\
LDL $(n=78)$ & $2.54(2.17,3.08)$ & $2.72(2.34,3.20)$ & 0.012 \\
ALT $(n=278)$ & $16.00(12.00,24.00)$ & $27.50(18.70,43.00)$ & 0.000 \\
AST $(n=278)$ & $19.00(16.00,24.00)$ & $26.00(21.00,33.00)$ & 0.000 \\
TP $(n=278)$ & $73.44 \pm 5.83$ & $72.32 \pm 6.32$ & 0.013 \\
G $(n=278)$ & $30.80 \pm 4.43$ & $29.59 \pm 5.57$ & 0.000 \\
ALB $(n=278)$ & $42.96 \pm 3.56$ & $42.92 \pm 3.93$ & 0.397 \\
PA $(n=278)$ & $246.75 \pm 47.07$ & $246.22 \pm 49.98$ & 0.856 \\
GGT $(n=278)$ & $18.00(14.00,30.10)$ & $26.20(19.00,48.60)$ & 0.000 \\
Hepatic/splenic CT ratio $(n=278)$ & $1.24(1.12,1.32)$ & $1.20(1.06,1.30)$ & 0.000 \\
PAT volume, cm ${ }^{3}(n=278)$ & $87.67 \pm 45.09$ & $104.25 \pm 47.74$ & 0.000
\end{tabular}

PAT, pericardial adipose tissue; TG, triglycerides; Chol, cholesterol; HDL, high density lipoprotein; LDL, low density lipoprotein; ALT, alanine aminotransferase; AST, aspartate aminotransferase; TP, total protein; G, globulin; ALB, albumin; PA, prealbumin; GGT, glutamyl transpeptidase; CT, computed tomography.

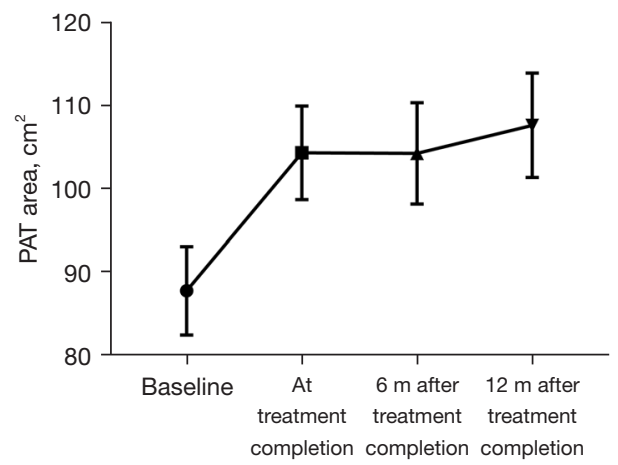

Figure 3 PAT volumes from baseline to 12 months after treatment completion. Error bars represent 95\% CIs. PAT, pericardial adipose tissue; CI, confidence interval.

regression analysis, the $\mathrm{P}$ values for differences in $\mathrm{BMI}$ at baseline and during the chemotherapy cycles were $<0.2$. In the multivariable model, only the 8th chemotherapy cycle was significantly associated with increased PAT volume as compared with the 4th cycle [odds ratio $(\mathrm{OR})=3.850 ; 95 \%$ confidence interval (CI): 1.751 to 8.488 ] (Table 3).

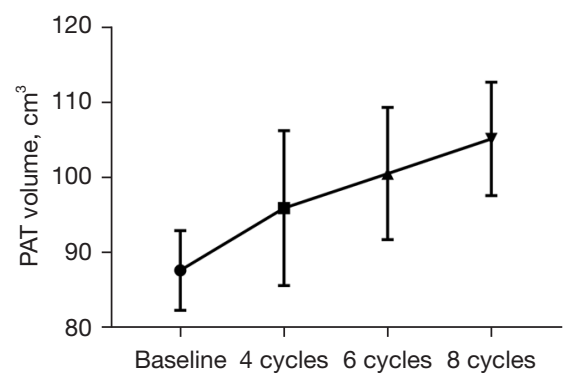

Figure 4 Comparison of PAT volumes in different chemotherapy cycles. Error bars represent 95\% CIs. PAT, pericardial adipose tissue; CI, confidence interval.

\section{Discussion}

In this cohort of breast cancer survivors, PAT volumes during chemotherapy were higher than at baseline and were maintained after chemotherapy, with statistically significant increases in the 6th and 8th cycles. In addition, volume gains at chemotherapy completion were primarily affected by the increases of chemotherapy cycles.

As the visceral fat stored around the heart, PAT 
Table 3 Univariate and multivariable logistic regression analyses of factors associated with increases in PAT volumes at chemotherapy completion

\begin{tabular}{|c|c|c|c|c|}
\hline Characteristics & \multicolumn{2}{|c|}{ Univariate regression analyses } & \multicolumn{2}{|c|}{ Multivariable regression analyses } \\
\hline Age, years & $1.016(0.986,1.047)$ & 0.291 & & \\
\hline \multicolumn{5}{|l|}{ Stage } \\
\hline $\mathrm{T} 1$ & Referent & & & \\
\hline T3 & $0.568(0.232,1.395)$ & 0.218 & & \\
\hline $\mathrm{T} 4$ & $1.036(0.500,2.147)$ & 0.925 & & \\
\hline Hypertension (at baseline), yes & $0.270(0.334,0.928)$ & 0.334 & & \\
\hline Diabetes (at baseline), yes & $1.234(0.417,3.232)$ & 0.669 & & \\
\hline$\geq 25 \mathrm{~kg} / \mathrm{m}^{2}$ & $1.380(0.347,1.033)$ & 0.137 & $1.408(0.918,2.160)$ & 0.118 \\
\hline TGs (at baseline), $\mathrm{mmol} / \mathrm{L}$ & $0.957(0.815,1.123)$ & 0.592 & & \\
\hline Chol (at baseline), $\mathrm{mmol} / \mathrm{L}$ & $0.946(0.691,1.293)$ & 0.725 & & \\
\hline Hepatic/splenic CT ratio >1.0 (at baseline) & $1.059(0.537,2.085)$ & 0.869 & & \\
\hline \multicolumn{5}{|l|}{ Cycles } \\
\hline 4 & Referent & & & \\
\hline 6 & $2.046(0.900,4.646)$ & 0.087 & $2.100(0.923,4.773)$ & 0.077 \\
\hline 8 & $3.811(1.735,8.365)$ & 0.001 & $3.850(1.751,8.488)$ & 0.001 \\
\hline
\end{tabular}

$P$ values were obtained from logistic regression analysis. All statistical tests were 2-sided. PAT, pericardial adipose tissue; OR, odds ratio; $\mathrm{Cl}$, confidence interval; BMI, body mass index; TG, triglycerides; Chol, cholesterol; CT, computed tomography.

participates in the process of coronary atherosclerosis by secreting multiple endocrine and paracrine factors $(3,17)$. There is a significant correlation between PAT volume, prevalence of coronary heart disease, and risk of future cardiac events $(18,19)$. Cardiovascular disease (CVD) is the second leading cause of long-term morbidity and mortality among cancer survivors (20) and the leading cause of death among female breast cancer survivors (21). Drug regimens containing anthracyclines are widely used in patients with breast cancer. Therefore, it is important to study PAT changes in patients undergoing this type of chemotherapy.

Previous longitudinal studies for breast cancer have consistently reported unfavorable long-term body composition changes, with a disproportionate increase in fat mass over muscle mass $(22,23)$. A study found that survivors of diffuse large B-cell lymphoma experienced adverse longterm body composition changes with increased visceral abdominal tissue (VAT) after chemotherapy (12).
However, the effects of anthracyclines on PAT volumes remain unclear. The current study found that PAT volumes began to increase as early as the 4th chemotherapy cycle, with statistically significant differences appearing from the 6th cycle. In addition, increased volumes were maintained 12 months after chemotherapy was completed, which is similar to findings reported in a previous study on VAT increases (12). There are 2 possible reasons for this: firstly, most patients with cancer lose weight prior to diagnosis and may purposefully gain weight after treatment until they return to their perceived normal (pretreatment) weight. Secondly, there is also evidence that breast cancer survivors decrease their levels of physical activity after diagnosis (24). The combination of increased caloric intake and decreased physical activity may contribute to the observed fat gain. Xiao et al. (12) found that the subcutaneous and visceral fat in diffuse large B-cell lymphoma survivors was significantly higher at 24 months after chemotherapy completion than 
at the time of chemotherapy completion. However, no statistically significant differences in PAT volume were observed at 6 and 12 months after chemotherapy in our study. This may be attributable to our relatively short follow-up time.

Levels of patients' liver enzymes, such as serum ALT and AST, were abnormal, and lipid metabolites such as TG and Chol increased significantly. Anthracyclines have been proven hepatotoxic. There are 2 main ways for anthracyclines to cause a pathological accumulation of lipids in hepatocytes: one is to activate peroxisome proliferator-activated receptor-gamma (PPAR-g) nuclear receptors to synthesize fatty acid, the other is to activate fatty acid translocase CD36 by activating adenosine monophosphate protein kinase (AMAPK) to promote the uptake of fatty acids. The CD36 protein has also been defined as a shared target of the hepatic nuclear receptors LXR and PXR, as well as PPAR- $\alpha$ and PPAR- $\gamma$ (25), which is consistent with the changes in lipid metabolites in this study. One explanation for increases in PAT volumes after chemotherapy may be that patients experience a degree of liver damage due to the hepatotoxicity of anthracyclines, which may affect lipid metabolism. Another reason may be that increases in LDL and decreases in HDL result in more Chol being carried into the pericardial tissue, from where it is more difficult to metabolize. A further possibility is anthracycline cardiotoxicity, which increases PAT. More research is needed to confirm these assumptions.

Our study found that completing 8 cycles of anthracycline-based chemotherapy was an independent risk factor for increased PAT volumes in patients with breast cancer and had a cumulative effect that was similar to anthracycline cardiotoxicity (26). Since PAT has significantly higher levels of a chemokine (MCP-1) and several inflammatory cytokines (IL-1 $\beta$, IL-6, IL-6sR, and TNF- $\alpha$ ) than subcutaneous fat, increased PAT in patients with breast cancer is a risk factor for CVD, which may affect patient survival and prognosis (27). Therefore, it is important to take preventative measures against CVD in patients with breast cancer who undergo 8 cycles of anthracycline-based chemotherapy.

Some recent studies have proposed that physical exercise can reduce PAT due to reductions in proinflammatory adipokines and improvements of inflammatory factors in the milieu of the coronary vessel wall (28-30). Other studies have reported that sodium-glucose cotransporter 2 inhibitors and glucagon-like peptide-1 receptor agonists can reduce PAT in patients with type 2 diabetes
$(31,32)$. Therefore, patients with breast cancer who receive anthracycline chemotherapy could be targeted for individualized lifestyle interventions, such as increased physical exercise and the abovementioned drugs, to prevent increases in PAT volume.

This study had several limitations. First, no male breast cancer patients were included in the study since the incidence is extremely low in males. Second, larger samples and multi-center studies are needed to find cut-off values to reduce major adverse cardiovascular events. Third, our follow-up period was relatively short. We will continue to follow-up the cardiovascular status of patients in the future and study the relationship between increased PAT volumes and major adverse cardiovascular events. Fourth, because the number of people treated with doxorubicin and pirarubicin was relatively small in this study, there were no subgroup analyses based on drug type. It is necessary to increase the sample size for subgroup analysis in future studies to assess the effects of different anthracyclines on PAT. Fifth, our software could not distinguish between paracardial adipose fat and EAT. There is a need to discover a way to accurately measure EAT volume. Finally, we did not include a healthy, age-matched control group, limiting the application of our findings to the general population. In future studies, comparisons will be made with a healthy and normal group over the same period to increase the general applicability of our findings.

In conclusion, this study described changes to PAT during and after chemotherapy treatment in patients with breast cancer. We demonstrated that patients with breast cancer who receive anthracycline-based chemotherapy undergo an unfavorable increase in PAT volume. Patients at risk for increases in PAT volume may be identified based on clinical factors. These high-risk patients could receive active intervention, including lifestyle changes and drug treatments that limit increases in PAT volume.

\section{Acknowledgments}

Funding: This study was funded by the National Natural Science Foundation of China (No. 82071883), the Fundamental Research Funds for the Central Universities in 2019 (No. 2019CDYGYB008), the Chongqing key medical research project of a combination of science and medicine (No. 2019ZDXM007), the 2019 SKY Imaging Research Fund of the Chinese International Medical Foundation (No. Z-2014-07-1912-10), Chongqing medical research project of a combination of science and medicine 
(No. 2021MSXM077), and Chongqing medical research project of a combination of science and medicine (No. 2021MSXM035).

\section{Footnote}

Reporting Checklist: The authors have completed the STROBE reporting checklist. Available at https://qims. amegroups.com/article/view/10.21037/qims-21-787/rc

Conflicts of Interest: All authors have completed the ICMJE uniform disclosure form (available at https://qims. amegroups.com/article/view/10.21037/qims-21-787/coif). $\mathrm{XZ}$ is employed by Siemens Healthcare. The other authors have no conflicts of interest to declare.

Ethical Statement: The authors are accountable for all aspects of the work in ensuring that questions related to the accuracy or integrity of any part of the work are appropriately investigated and resolved. The study was conducted in accordance with the Declaration of Helsinki (as revised in 2013). The study was approved by the ethics committee of the Chongqing University Cancer Hospital, and individual consent for this retrospective analysis was waived.

Open Access Statement: This is an Open Access article distributed in accordance with the Creative Commons Attribution-NonCommercial-NoDerivs 4.0 International License (CC BY-NC-ND 4.0), which permits the noncommercial replication and distribution of the article with the strict proviso that no changes or edits are made and the original work is properly cited (including links to both the formal publication through the relevant DOI and the license). See: https://creativecommons.org/licenses/by-nc-nd/4.0/.

\section{References}

1. Madonna R, Massaro M, Scoditti E, Pescetelli I, De Caterina R. The epicardial adipose tissue and the coronary arteries: dangerous liaisons. Cardiovasc Res 2019;115:1013-25.

2. Matafome P. Epicardial adipose tissue (dys)function: A new player in heart disease? Rev Port Cardiol (Engl Ed) 2020;39:635-7.

3. Iacobellis G. Local and systemic effects of the multifaceted epicardial adipose tissue depot. Nat Rev Endocrinol 2015;11:363-71.
4. Wu B, Ren Z, Du Z, Zhang L, Hou B. The relationship between quantitative epicardial adipose tissue based on CT and coronary artery disease: A protocol for systematic review and meta-analysis. Medicine (Baltimore) 2020;99:e23729.

5. Lu YY, Huang SY, Lin YK, Chen YC, Chen YA, Chen SA, Chen YJ. Epicardial adipose tissue modulates arrhythmogenesis in right ventricle outflow tract cardiomyocytes. Europace 2021;23:970-7.

6. Nerlekar N, Muthalaly RG, Wong N, Thakur U, Wong DTL, Brown AJ, Marwick TH. Association of Volumetric Epicardial Adipose Tissue Quantification and Cardiac Structure and Function. J Am Heart Assoc 2018;7:e009975.

7. Zhu L, Gu S, Wang Q, Zhou X, Wang S, Fu C, Yang W, Wetzl J, Yan F. Left ventricular myocardial deformation: a study on diastolic function in the Chinese male population and its relationship with fat distribution. Quant Imaging Med Surg 2020;10:634-45.

8. Iacobellis G, Corradi D, Sharma AM. Epicardial adipose tissue: anatomic, biomolecular and clinical relationships with the heart. Nat Clin Pract Cardiovasc Med 2005;2:536-43.

9. Bertaso AG, Bertol D, Duncan BB, Foppa M. Epicardial fat: definition, measurements and systematic review of main outcomes. Arq Bras Cardiol 2013;101:e18-28.

10. Emamat H, Tangestani H, Behrad Nasab M, Ghalandari $\mathrm{H}$, Hekmatdoost A. The association between epicardial adipose tissue and non-alcoholic fatty liver disease: A systematic review of existing human studies. EXCLI J 2021;20:1096-105.

11. Reding KW, Brubaker P, D’Agostino R Jr, Kitzman DW, Nicklas B, Langford D, Grodesky M, Hundley WG. Increased skeletal intermuscular fat is associated with reduced exercise capacity in cancer survivors: a crosssectional study. Cardiooncology 2019;5:3.

12. Xiao DY, Luo S, O'Brian K, Sanfilippo KM, Ganti A, Riedell P, Lynch RC, Liu W, Kahl BS, Cashen AF, Fehniger TA, Carson KR. Longitudinal Body Composition Changes in Diffuse Large B-cell Lymphoma Survivors: A Retrospective Cohort Study of United States Veterans. J Natl Cancer Inst 2016;108:djw145.

13. Deckers JG, Schellevis FG, Fleming DM. WHO diagnostic criteria as a validation tool for the diagnosis of diabetes mellitus: a study in five European countries. Eur J Gen Pract 2006;12:108-13.

14. Whelton PK, Carey RM, Aronow WS, Casey DE Jr, 
Collins KJ, Dennison Himmelfarb C, et al. 2017 ACC/ AHA/AAPA/ABC/ACPM/AGS/AphA/ASH/ASPC/ NMA/PCNA Guideline for the Prevention, Detection, Evaluation, and Management of High Blood Pressure in Adults: A Report of the American College of Cardiology/ American Heart Association Task Force on Clinical Practice Guidelines. Circulation 2018;138:e484-594.

15. Oh SW, Shin SA, Yun YH, Yoo T, Huh BY. Cutoff point of BMI and obesity-related comorbidities and mortality in middle-aged Koreans. Obes Res 2004;12:2031-40.

16. Chon YE, Jung KS, Kim SU, Park JY, Park YN, Kim DY, Ahn SH, Chon CY, Lee HW, Park Y, Han KH. Controlled attenuation parameter (CAP) for detection of hepatic steatosis in patients with chronic liver diseases: a prospective study of a native Korean population. Liver Int 2014;34:102-9.

17. Cheng KH, Chu CS, Lee KT, Lin TH, Hsieh CC, Chiu CC, Voon WC, Sheu SH, Lai WT. Adipocytokines and proinflammatory mediators from abdominal and epicardial adipose tissue in patients with coronary artery disease. Int J Obes (Lond) 2008;32:268-74.

18. Greif M, Becker A, von Ziegler F, Lebherz C, Lehrke M, Broedl UC, Tittus J, Parhofer K, Becker C, Reiser M, Knez A, Leber AW. Pericardial adipose tissue determined by dual source CT is a risk factor for coronary atherosclerosis. Arterioscler Thromb Vasc Biol 2009;29:781-6.

19. Mancio J, Azevedo D, Saraiva F, Azevedo AI, Pires-Morais G, Leite-Moreira A, Falcao-Pires I, Lunet N, Bettencourt N. Epicardial adipose tissue volume assessed by computed tomography and coronary artery disease: a systematic review and meta-analysis. Eur Heart J Cardiovasc Imaging 2018;19:490-7.

20. Mertens AC, Liu Q, Neglia JP, Wasilewski K, Leisenring W, Armstrong GT, Robison LL, Yasui Y. Cause-specific late mortality among 5-year survivors of childhood cancer: the Childhood Cancer Survivor Study. J Natl Cancer Inst 2008;100:1368-79.

21. Patnaik JL, Byers T, DiGuiseppi C, Dabelea D, Denberg TD. Cardiovascular disease competes with breast cancer as the leading cause of death for older females diagnosed with breast cancer: a retrospective cohort study. Breast Cancer Res 2011;13:R64.

22. Demark-Wahnefried W, Peterson BL, Winer EP, Marks L, Aziz N, Marcom PK, Blackwell K, Rimer BK. Changes in weight, body composition, and factors influencing energy balance among premenopausal breast cancer patients receiving adjuvant chemotherapy. J Clin Oncol 2001;19:2381-9.

23. Irwin ML, McTiernan A, Baumgartner RN, Baumgartner KB, Bernstein L, Gilliland FD, Ballard-Barbash R. Changes in body fat and weight after a breast cancer diagnosis: influence of demographic, prognostic, and lifestyle factors. J Clin Oncol 2005;23:774-82.

24. Irwin ML, Crumley D, Mc'Tiernan A, Bernstein L, Baumgartner R, Gilliland FD, Kriska A, Ballard-Barbash R. Physical activity levels before and after a diagnosis of breast carcinoma: the Health, Eating, Activity, and Lifestyle (HEAL) study. Cancer 2003;97:1746-57.

25. Jing X, Sun C, Chen H, Sun J, Zhang Y, Wu J. Protection of paeonol against epirubicin-induced hepatotoxicity: A metabolomic study. Biosci Trends 2019;13:253-60.

26. Ryberg M, Nielsen D, Cortese G, Nielsen G, Skovsgaard T, Andersen PK. New insight into epirubicin cardiac toxicity: competing risks analysis of 1097 breast cancer patients. J Natl Cancer Inst 2008;100:1058-67.

27. Mazurek T, Zhang L, Zalewski A, Mannion JD, Diehl JT, Arafat H, Sarov-Blat L, O'Brien S, Keiper EA, Johnson AG, Martin J, Goldstein BJ, Shi Y. Human epicardial adipose tissue is a source of inflammatory mediators. Circulation 2003;108:2460-6.

28. Colonetti T, Grande AJ, Amaral MC, Colonetti L, Uggioni ML, da Rosa MI, Hernandez AV, Tse G, Liu T, Nerlekar N, Biondi-Zoccai G, Neto MG, Durães AR, Pontes-Neto O, Resende ES, Roever L. Effect of exercise on epicardial adipose tissue in adults: a systematic review and meta-analyses. Heart Fail Rev 2021;26:1399-411.

29. Tanaka K, Fukuda D, Sata M. Roles of Epicardial Adipose Tissue in the Pathogenesis of Coronary Atherosclerosis - An Update on Recent Findings. Circ J 2020;85:2-8.

30. Kim MK, Tomita T, Kim MJ, Sasai H, Maeda S, Tanaka K. Aerobic exercise training reduces epicardial fat in obese men. J Appl Physiol (1985) 2009;106:5-11.

31. Yagi S, Hirata Y, Ise T, Kusunose K, Yamada H, Fukuda D, Salim HM, Maimaituxun G, Nishio S, Takagawa Y, Hama S, Matsuura T, Yamaguchi K, Tobiume T, Soeki T, Wakatsuki T, Aihara KI, Akaike M, Shimabukuro M, Sata M. Canagliflozin reduces epicardial fat in patients with type 2 diabetes mellitus. Diabetol Metab Syndr 2017;9:78

32. Dutour A, Abdesselam I, Ancel P, Kober F, Mrad G, Darmon P, Ronsin O, Pradel V, Lesavre N, Martin JC, 
Jacquier A, Lefur Y, Bernard M, Gaborit B. Exenatide decreases liver fat content and epicardial adipose tissue in patients with obesity and type 2 diabetes: a prospective randomized clinical trial using magnetic resonance imaging and spectroscopy. Diabetes Obes Metab 2016;18:882-91.

Cite this article as: Chen Q, Tu C, Li X, Shen H, Wang X, Liu D, Wang Y, Liu R, Den W, Zhang X, Zhang J. Longitudinal pericardial adipose tissue changes in patients with breast cancer receiving anthracycline-based chemotherapy: a retrospective cohort study. Quant Imaging Med Surg 2022;12(4):2416-2426. doi: 10.21037/qims-21-787 